\title{
A Comparison Between an Individual and a Collaborative Versions of a Serious Game to Learn About Dengue Fever
}

\section{Um Jogo Sério Colaborativo Para Aprender Sobre a Doença da Dengue}

\begin{abstract}
Dengue fever is a major infectious disease caused by arbovirus and there is no vaccine yet; prevention is the action which raises the importance of an educational approach. The use of games to help in the educational process can be motivating and effective but it is not clear which interaction approach is the best: individual or collaborative. A comparative study on a between subject experiment using a single-player and a pair-based version of a Serious Game that teaches about Dengue fever has been performed. Further analysis (totaling 113 participants - players) assessed game's content, functions and feedbacks regarding motivation and satisfaction. Both versions performed well but presented different advantages: single-player version seems to be better used for quick and focused consulting, and the pair-based version seems to be slightly more motivating to the point that players would be more willing to suggest it to someone else. As a whole, data suggest that each interaction approach has its role in the educational process with a small edge towards the collaborative version, and should be carefully evaluated against educator's intents.

Keywords: Dengue fever. Serious games. Education. Collaborative learning.
\end{abstract}

Resumo: A dengue é uma doença infecciosa grave causada por arbovírus e não existe vacina ainda; há a necessidade de uso de abordagens educativas para enfatizar a prevenção desta doença. O uso de jogos como ferramentas para o processo educacional pode ser motivador e eficaz, mas não está claro qual a abordagem de interação é a melhor: individual ou colaborativo. Um estudo comparativo foi realizado através de um experimento entre-grupos $(n=73)$ utilizando uma versão individual e outra colaborativa entre pares de um jogo sério que ensina sobre dengue. Ambas as versões foram bem avaliadas, mas com diferentes vantagens: a versão individual pode ser utilizada mais facilmente para consulta, ao passo que a versão colaborativa se mostrou um pouco mais motivadora ao ponto que os jogadores estariam mais dispostos a sugeri-lo a outras pessoas. Os dados sugerem que cada abordagem de interação tem o seu papel no processo educativo e deve ser cuidadosamente avaliada com relação as intenções do educador.

Palavras-chave: Dengue. Jogos Sérios. Educação. Aprendizagem colaborativa.

BUCHINGER, Diego; HOUNSELL, Marcelo da Silva. A Comparison Between an Individual and a Collaborative Versions of a Serious Game to Learn About Dengue Fever. Revista Informática na Educação: teoria e prática, Porto Alegre, v. 18, n. 1, p. 67-84, jan./jun. 2015.

\section{Diego Buchinger}

\author{
Marcelo da Silva Hounsell \\ Universidade do Estado de Santa
}

\section{Introduction}

S chools have been facing the need for different ways of teach using new technologies as a motivational reinforcement for youngsters. At the same time, computer games increase its space in the international market and have already drawn attention from educational institutions.

Serious games are computer applications that merge serious aspects such as teaching, learning, communication and information with the playful interaction provided by the video games where the main purpose is beyond pure entertainment (ALVAREZ; DJAOUTI, 2011). Differently from Commercial Off-the-Shelf (COTS) games, serious games are designed 
specifically for learning, skill acquisition and training purposes from the very beginning. However, there is no consistent definition for this term yet and little guidance about serious game development can be found (BOYLE; CONNOLLY; HAINEY, 2011).

Since the 1980s, researchers have been talking about videogames as a model to enhance the learning environments with clear objectives, challenges and collaboration, giving the learning control process to the students (BOWMAN, 1982). However, the main focus of videogames discussion in that decade was on the social consequences of its use: the fear of individualization - omission of social interactions - in the learning process (CORTE et al., 2003). The same individualization was sought in common learning practice at schools, where students have been asked to work alone, even when the majority of the researches highlighted the effectiveness of cooperation (JOHNSON, R.T.; JOHNSON, D., 1988).

Over the years however, this context has changed: people started to seek the communication and interaction benefits of computer games. There are researches in the 21 st century that used these new technological possibilities in order to facilitate the social interaction among teachers and students, as well as students among themselves (CORTE et al., 2003). Also, researches began to question the fear of social isolation when using individual games, since players talk about experiences in subsequent interactions with friends, even when they have played alone beforehand (STENROS; PAAVILAINEN; MÃYRÃ, 2009).

Collaborative work is an ever so demanding requirement for the work force and, for the learning process, it is agreed that it also helps learning. Collaboration is a skill that can be taught and developed, even on videogames, but not so many serious games present this feature, leading to new questionings that are still to be answered properly, like: would a collaborative version of an educational game promote higher learning, interaction, satisfaction and motivation than a standalone version of the same game? How players would feel about their partners on a collaborative game? What are the differences and applications of a standalone to a collaborative game?

In order to investigate the player perception when playing collaboratively or individually, two serious games were developed following the same base guidelines in terms of contents, looks and elements of interaction, but one is an individual version while the other is a collaborative version. Both games tackle dengue fever as the subject matter and were targeted to children and youngsters.

Dengue fever is an endemic disease that affects tropical and subtropical countries in the Asia-Pacific region, Americas, Middle East and Africa. In the Americas, the epidemiology of dengue was recently reviewed; Guzman and Istúriz (2010) emphasize the great increase of reported cases in this specific area during the last three decades. In Brazil, where recent outbreaks occurred, during the last decade, an increase from 228 thousand to 1 million reported cases have occurred (BRASIL, 2013). It is estimated that about 50-100 million humans are infected annually, where 22 thousand of them die (GUZMAN; ISTÚRIZ, 2010).

Since the dengue fever is an ever present disease in many countries and does not have a vaccine available yet, it would be better to educate people - especially kids and teenagers - about this disease and its prevention. It would be reasonable to use a computer game in this case because people nowadays are attracted to this type of media. This could encourage people to fight against dengue through the elimination or treatment of places where 
the mosquitoes - the disease vector - deposit their eggs. Doing so, a reduction in the mosquitoes breeding cycle can be reached, reducing the disease cases.

The two serious games developed are part of a sequel named Sherlock Dengue (SD) that mixes desktop virtual reality with the dengue fever problem. The individual version of the sequel is the SD version 2 (SDV2) and the collaborative version is the SD version 6 (SDv6). Although these games were developed using different approaches the content and gameplay were kept as similar as possible.

The objective of this paper is to present a comparison between players' perception when playing the individual or the collaborative version of SD. A preliminary between-subject study with 53 participants was conducted in order to investigate satisfaction and motivation while playing both versions of the game.

This paper is structured as follows: in chapter 2 a literature review is presented, in chapter 3 a summary of Sherlock Dengue's project is shown, revealing what have been done so far, but emphasizing the SDv2 individual version and the SDv6 collaborative version, in chapter 4 this study methodology is presented, in chapter 5 the results and the analysis of the collected data are shown and discussed, in chapter 6 the conclusions are presented, followed by the acknowledges and references.

\section{Related Works}

In order to find related works, two search lines were sought: games about dengue, and studies about collaboration's role in the learning process - the so called Computer-Supported Collaborative Learning ( $\mathrm{CSCL}$ ).

\subsection{Games about Dengue}

As a global problem, several approaches were conducted around the globe, especially in the tropics where the disease is more active.

Lennon and Coombs (2006) studied the influence of gaming in the dengue's learning process in The Philippines, but with a board game (Goodbye-to-Dengue); they claim the board games are adaptable, cheap, and promotes independent learning. The game uses interactive cards to present dengue's content, addressing the mosquito characteristics, disease control, treatment, disease signs and symptoms, and the reinforcement is obtained through the answers to the game's questions. Lennon and Coombs (2006) analyzed the learning efficacy in knowledge, attitudes-beliefs, and self-efficacy, in a group of 168 children and teenager from private schools in The Philippines. The experiment used between subjects design, where the students were split into two groups: one that just used the game and other that just took classes about the subject. The results shown the group that took just classes had better knowledge results, both groups had insignificant raise in attitudes-beliefs index, and the self-efficacy had a significant grow in both groups. Despite the knowledge results has shown better improvement on the group that took just classes, Lennon and Coombs (2006) argues that this group performance depends on lecturers skills and experiences, and for this study, the best teacher among the student teacher population was chosen as lecturer.

From Venezuela, Vivas and Sequeda (2003) studied the efficacy of a game (Jugando em salud: dengue - Playing for health: dengue) as a learning tool for control and prevention against the dengue fever disease and its vector in the area, the Aedes Aegypti. The game - develo- 
ped with international support (Pan American Health Organization and World Bank) - was designed to educate Venezuelan school children about dengue, arouse their motivation, curiosity and participation. There were 621 attendees in the experiment, ranging from 8 to 16 years old, which were split in three groups (between subjects experiment design). The first group should use the game three times per week, in a period of sixty days, and their teachers received new theoretical materials about dengue; the second group was benefited from new material, but not the game; and the third group do not received any extra material, following just the regular learning program. All the three groups were evaluated with questionnaires before and after the program, where the first and the second group had a bigger increase in dengue knowledge. In addition, the game had shown to be well accepted by its players.

In Brazil, Silva et al. (2011) introduced a Role Playing Game (RPG) about dengue fever (Exterminadores de dengue - Dengue terminators) in which the players learn about the disease in a virtual environment that highlights the local geography, living standards and culture. The game's story takes place in a fictional town, when the player's avatar learns that one of his/her relatives has contracted dengue fever. The gameplay basis is to eliminate the disease vectors - in RPG battle style - and its deposit spots, while finding and bringing medicines to his/her relative, to learn vital information and to get tools with non-player characters. The game was under development and no experiment using this game was conducted yet.

Another Brazilian game ${ }^{1}$ (Contra Dengue Against Dengue) was introduced by Pereira et

\footnotetext{
1 Site: <http://www.ludoeducajogos.com.br/site/jogos/contra-a-dengue $>$.
}

al. (2011). It is an arcade game, similar to the very popular Mario World, where the player has to explore the environment, overcome obstacles and eliminate deposit spots for mosquitoes. In addition, while wandering through the game, the player may find items for restore his life, extra chances to continue if he loses, and medals to earn more points. The target audiences are children and teenagers, but no studies about its use were reported by Pereira et al. (2011).

There are also many online games ${ }^{2}{ }^{4}$ available dealing with the dengue fever issue, but they lack content regarding the disease which is presented separately - in the main menu the player could choose between play the game or read the content - and the game's main focus is on entertainment. Furthermore, these games have the same 2D Flash ${ }^{\mathrm{TM}}$ look and feel.

\subsection{Computer-Supported Collabora- tive Learning}

Many studies concerning the use of collaborative educational games in the learning process have been conducted in the recent years. Collazos et al. (2007) evaluated the collaborative learning process (collaborate to learn) and the learning of how to collaborate process in small groups working synchronously, using six tools. In their study they suggested a set of five system-based indicators of success on collaborative learning - use of strategies, intra-group cooperation, reviewing success criteria, monitoring and performance - that could be measured by proposed metrics.

\footnotetext{
${ }^{2}$ Dengue - <http://mrjogos.uol.com.br/jogo/dengue.jsp $>$. ${ }^{3}$ Dengue Buster - <http://www.tomsgames.com/game-6301-play-dengue-buster.php>.

4 Combater a Dengue - <http://mrjogos.uol.com.br/jogo/ combater-a-dengue.jsp >
} 
Sung and Hwang (2013) investigated the efficacy of the Mindtool-assisted collaborative game-based learning approach in learning achievements, attitudes toward science, motivation, and group learning. A repertory grid-assisted collaborative educational game - using a RPG style subsystem and an area for collaborative knowledge construction - was developed for the elementary school natural science course, addressing to plants recognition in a fantasy story, where the players had to fill their repertory grid by collecting detailed information about specific plants, or by discussing collaboratively with their peers. Ninety-three sixth graders students divided in three classes were guided to organize knowledge of differentiating plants using the presented game, in one hundred minutes. In the between subjects experiment, one class - the experimental group - learned with the collaborative game with the repertory grid approach; the other class - the first control group - learned with the conventional collaborative game without using repertory grids; and the last class - the second control group - learned with the game individually, but developing their own repertory grids. The results showed a significant increase in the experimental group learning achievements, learning attitudes toward science, motivation and self-efficacy. Although the main attention in this study was focused on the use of a repertory grid in collaborative games, Sung and Hwang (2013) have compared a collaborative and an individual version of the same game.

Bilsen, Bekebrede and Mayer (2010) used a simulating game for complex adaptive systems understanding. It is a multiplayer simulation game (SimPort-MV2) which simulates the complex adaptive systems of the port extension Maasvlakte in Holland, requiring several decisions to be made. According to Bilsen, Beke- brede and Mayer (2010), a simulation game was chosen to teach about complex adaptive systems because it could provide a decision support method with realistically human players, social interactions, physical and social rules. In their study, 415 people used the SimPort-MV2 and after playing, the participants agreed the game is educative, enjoyable, detailed, realistic, and promotes communication and cooperation, being a motivating environment to get insights of complex systems. The focus of Bilsen, Bekebrede and Mayer (2010) study was not in the collaborative aspect, but in the game's content.

Padrós, Romero and Usart (2012) attempted to measure the knowledge convergence process - where more than one person reach a mutual understanding after a social and cooperative interaction in a task, with similar knowledge - using a collaborative game called MetaVals. This game has the objective of teach finance concepts, through a collaborative (two players) classification of items as assets or liabilities, where the players should agree in a final answer. Seventy finance post-graduate students participated in an experiment, playing collaboratively in pairs in various situations: fully online, face-to-face, synchronous, or even asynchronous. The data was collected in pre, on and post task stage, which indicated higher improvement in the learning performance of participants with lower domain knowledge.

A controlled experiment was held by Hämäläine et al. (2006), aiming to promote collaboration between players and the learning of how to collaborate, using a 3D collaborative game (eScape) - a four player social action adventure game, where the players had to work collaboratively on a set of problems in order to escape from the scenario - in which 24 university students played for 60 minutes. The data analysis indicated most groups achieved a high 
level collaboration, but an initial individualistic behavior was seen, where the tasks compelling the players to work together were the key for fostering the collaboration. In addition, there were significant differences in the spent time, collaboration degree, assumed roles and the attitudes among the groups.

Zea et al. (2009) listed recommended elements in collaborative educational videogames as a guideline to follow, and then analyzed their involvement with three vital layers in the videogame architecture: game core, game engine and game interface. They presented the redesign of a single player videogame (Leoncio on the Island of the Lost Vowels) for young children (three to four years old) into a collaborative educational game, using their suggested guideline. No evaluating method was used.

In some way similar to the Zea et al. (2009) study, Kemczinski, Marek and Hounsell (2007) also presented a study that provided some guidelines for collaborative and cooperative characteristics. In this research the relation between collaboration and cooperation was investigated, where an intersecting relationship was defended. To indicate some differences between the two processes, a list of system's aspects were argued to be more inclined to support one than the other and vice versa.

Paraskeva, Mysirlaki and Papagianni (2010) also investigated collaborative learning in multiplayer online games. Several researches about game trends were revised including aspects like frequency of game play, game preferences and academic performance. Also, the development of multiplayers educational games based on an activity theory system was proposed but just in theory.

\subsection{Discussion}

There are many games about dengue, but their content is nonexistent or very limited, and in several cases not directly linked to the game play. In other cases there are two components of the game: the game itself and attached information. This strategy suggests players that, there are the fun and entertaining side, and the boring and tiring side, what goes in the opposite direction of the serious games purpose. What must be sought in serious game is how to merge, in an interesting way, the information, habit or experience with a gameplay.

All the videogames found were $2 \mathrm{D}$ and most of them do not report if they are open source or not. In the literature and also in the internet, the search for collaborative videogame dealing with the dengue issue or even just a $3 \mathrm{D}$ videogame about dengue fever returned no results. Also, one could notice that online games, with few exceptions, were much more inclined to entertain rather than teach, whereas the academic-breed games were more inclined to teach rather than entertain.

Computer-Supported Collaborative Learning studies mainly concerns to the improvement of the learning process using the collaborative aspect and how to foster the most of collaboration between groups of players. There are lots of questions to be answered and one of them, that was underexplored, is the relation of motivation and satisfaction between a collaborative and a single player serious game.

\section{Sherlock Dengue}

The Sherlock Dengue's (SD) project is an initiative to bring people's attention to virtual reality and related technologies toward the 
public health issue of dengue fever (SCHMITZ; KEMCZINSKI; HOUNSELL, 2004). This project embraces the development of serious games using different game designs and technologies intending to present general dengue information interactively (SHERLOCK..., 2013).

The name of the project refers to the famous detective Sherlock Homes and his skills to look thoroughly for clues, or in this case, the whereabouts of mosquitoes' eggs. Currently, SD is the only 3D computer game sequel existing so far that addresses to dengue fever. Its target audiences are children and teenagers aged between 8 to 15 years old. With the development of a collaborative version of the game, and a new version for health professionals, at this very moment, the SD sequel has eight versions, all freely available in Portuguese language.

Sherlock Dengue has been evolving through various improvements and technologies (SHERLOCK..., 2013): SDv1 The Begins - focus on old beliefs of true and false mosquito deposit spots (SCHMITZ et al., 2004); SDv2 It is Everywhere - the player have to interact with four kinds of objects for learn more about dengue and answer to questions about this subject, in order to earn points and move on to the next levels (HOUNSELL et al., 2006a); SDv3 Buzzing Around - an improvement of the previously version, including sound effects and speeches (HOUNSELL et al., 2006b); SDv4 Augmenting the Search - introduced the use of augmented reality technology in the gameplay (TREVISAN et al., 2009); SDv5 The Eliminator - used Flash technology to create a different gameplay, focusing in the match of each mosquito deposit spots with the correct item or procedure used to clean it up (HOUNSELL; MIRANDA; KEMCZINSKI, 2010); SDv6 You are not Alone - the collaborative version introduced in this paper; SDV7 PRO - a version with more challenging questions, recommended for health professionals (doctors and health agents); and SDV8 The Neighborhood - a new redesigned version with improved graphics and interactions that included a collaborative-competitive (pair duel) gameplay (BUCHINGER; HOUNSELL, 2014). Despite the changes and improvements that have been made, all these versions have kept the look, feel and educational focus of the game.

\subsection{Sherlock Dengue's Gameplay}

In this paper we focus on the SDv2 and SDv6. In fact, the main reference to conceive the game play of SDv6 was the SDV2, and it was chosen because it is a standalone version, easy to use, stable and it has been the reference for the other versions so far. Both in the second and sixth version, there are eight levels that take place in two different 3D scenarios - a mid-class apartment environment and a shanty house environment - in which there are essentially four kinds of interactive objects:

- The facts (Figure 1-A): represented by books floating around; present textual information related to the dengue disease such as its symptoms and treatment, prevention, the mosquito vector Aedes Aegypt and Aedes Albopictus, and the disease cycle;

- The mosquito DEPOSIT SPOTS (Figure 1-B): represented by several objects such as tires in the garden, cans with water, and flower vases. When the player interacts with them, a multiple choice question about dengue is presented to him. If it is correctly answered the player earn points (ranging from 10 to 30 points, according to the difficulty), otherwise 
he loses points $(-33 \%$ over the obtainable points from that particular question) but he is able to answer it again and get points later. The mosquito DEPOSIT SPOTS are always linked to a FACT: the questions in them refer back to the information given by a fact in previous level;

- The REMinders (Figure 1-C): represented by big yellow post-it's also floating around that brings again (in the current level) the information presented in FACTS of the previous level. The REMINDERS are also always linked to a mosquito DEPOSIT SPOT, appearing in the same level however, its use reduce the obtained points by $50 \%$ when answering the related question (i.e. if the question value is 30 points, the player would earn just 15 points), but also, it decrease the losing points from $-33 \%$ to $-25 \%$ over attainable points (i.e. if the player answer wrongly a question of 30 points, normally he would lose 10 points, but if he had used the REMINDER he would lose only 8 points). This strategy value the player to go after the actual information than doing a trial-error attempt;

- The CURIOSITIEs (Figure 1-D): represented by big mosquitoes with a question mark above their heads that presents additional information - usually historical data - about dengue fever that would not be asked to the player in questions.

The player of SDV2 plays the role of a dengue virtual inspector, where the main objective is to earn points for finding the mosquito DEPOSIT SPOTS and answering the questions - reinforcement through answering questions, similarly with Lennon and Coomb (2006) approach - in order to pass through all levels and, in the process, learn about dengue fever.
Initially the player will start in a scenario where FACTS present information needed to answer questions in the next level. From the second to the seventh level, there will be curiosities, mosquito DEPOSIT SPOTS, REMINDERS and FACTS. Finally in the eighth and final level, there will be again all the interactive objects except for the FACTS. To jump from one level to the next one, the player needs to earn a minimum amount of points, ranging from $40 \%$ to $70 \%$ over the maximum attainable points, except for the first level, where he/she can move on at any time, because there is no question.

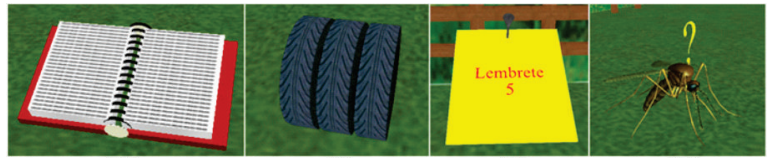

$$
\text { (A) }
$$

(B)

(C)

(D)

FIGURE 1 - Sherlock Dengue's interactive objects:

(A) FACTS, (B) mosquito DEPOSIT SPOTS, (C) REMINDERS, and (D) CURIOSITIES.

SOURCE: Our authorship

It is important to notice that one player should not complete a level without reading the FACTS, because if he tries to use just the REMINDERS in order to answer correctly the questions, he will not obtain enough points to move to the next level. Similarly, if the player uses the trial and error method, he would have one quarter of chance to be correct in each of the seven questions, and most likely he will not obtain the minimum required points.

\subsection{Collaborative Sherlock Dengue}

The main motivation to create a distributed collaborative version of SD was the attempt to increase the player interaction with the game and the learning content. Collaboration is a way to emphasize the workgroup and social interactions. 
To conceive the collaborative version for $\mathrm{SD}$, some alternatives about how to create an attractive collaborative gameplay without changing the principles of the SDv2 have been considered. Criteria presented by Kemczinski, Marek and Hounsell (2007) were used to drive and check the collaboration degree intensity promoted by the environment. At the end of this process we came up with a shared virtual environment for two players, where each one controls its own avatar - with the same capabilities - provided with a chat to allow the communication between players.

The gameplay itself had to be changed in order to adapt to the collaborative dynamics, but the tridimensional environments, basic gameplay and objects from the individual version were reused in this new version. Also, the database with dengue fever's questions and information were all kept the same.

Despite both versions being implemented with different technologies - the SDV2 used $\mathrm{HTML}, \mathrm{PHP}^{5}$ and $\mathrm{X}^{3 \mathrm{D}^{6}}$ while the collaborative version SDv6 used JAVA ${ }^{7}, \mathrm{RMI}^{8}$ and $\mathrm{Xj}^{3} \mathrm{D}^{9}$ technologies - we aimed to keep the looks, feel and contents as similar as possible. The result can be seen comparing Figure 2, which shows a SDv2 screen of an apartment environment, and Figure 3, which shows a SDv6 screen of a poor shanty house. Each numbered circle represents a specific area of the game. The circles displays: (1) feedback and information area, (2) visual 3D area, (3) status area, (4) question area, (5) level control area, and (6) chat area (exclusive for SDv6).

\footnotetext{
5 Eletronic mail: <http://php.net/>.

${ }^{6}$ Eletronic mail: <http://www.web3d.org/x3d/>.

7 Eletronic mail: <http://www.java.com>.

8 Eletronic mail: <http://www.oracle.com/technetwork/java/ javase/tech/index-jsp-136424.html>.

${ }^{9}$ Eletronic mail: <http://www.xj3d.org/>.
}

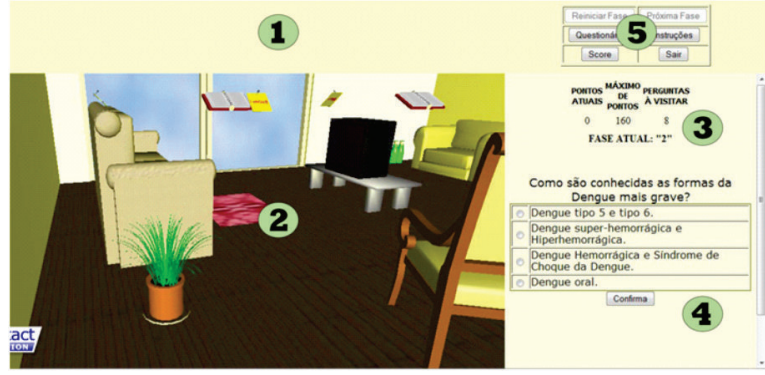

FIGURE 2 - The apartment environment in the Sherlock Dengue v2 game. SOURCE: Our authorship

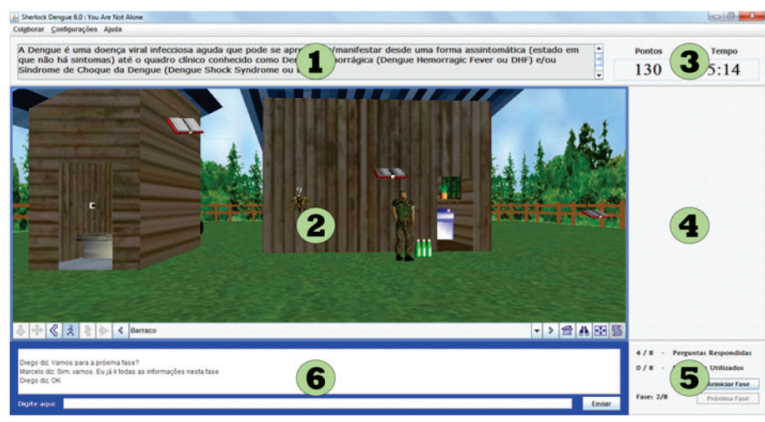

FIGURE 3 - The poor shanty house environment in the Sherlock Dengue v6 game. SOURCE: Our authorship

Nevertheless, with different technologies, system's requirements for each game are different. SDV2 is playable at a web browser that supports X3D visualization, and SDv6 needs Java with the binary codes of the Xj3D.

Some of the SDv6 gameplay characteristics include:

- Collaboration restricted to a pair of players due to the game chosen strategy;

- Free movement and a countdown timer was included, where the time is the same for both players, as well as the score;

- To foster exploration and communication, a remunerative chat that analyses the input text was adopted, granting 
additional time to the pair according to the correctness and size of the text;

- The chat uses visual and auditory alerts to notify new messages;

- The 'curiosities' have a new functionality: now the pair earns time when finding and interacting with them;

- Collaborative decisions were introduced, requiring approval from the collaborator - because both players will be affected - for restarting the current level, advancing to the next level or consulting the REMINDER;

- To proceed to the next level, both players have to answer correctly some questions, because one player cannot obtain alone the minimal required points.

\subsection{Game's Communication Architec- ture}

As the single player and the collaborative Sherlock Dengue's versions use different technologies, the architecture for both games are distinct. While SDV2 uses the internet architecture where there is one server and several clients requesting data, SDv6 uses unusual client-server architecture with one server for every two clients (Figure 4). In the collaborative version, the server works as a mediator between the clients, passing on game's information such as: updated current time, chat messages and, requests for using reminders or to restart the current stage.

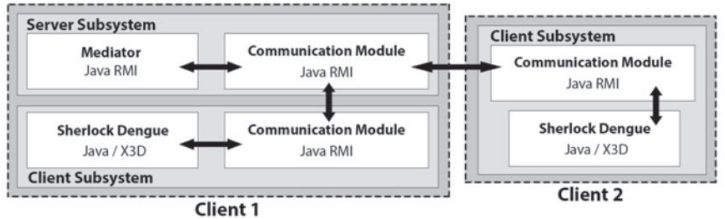

FIGURE 4 - SDv6 communication architecture. SOURCE: Our authorship
The SDv6 server was reused from another collaborative application (DIAS et al., 2011) and improved for better efficiency and automation of game initialization. The server was bounded to the client application, being started when a player chose to create a new game. In this way, the first player has to create a new game while the second player needs to input his collaborator IP address to enter in the game.

\section{Methodology}

To check the satisfaction and motivation in both SDv2 and SDv6, a questionnaire with eleven questions addressing the game's functions and the content about dengue fever was composed (Table 1). There are nine multiple choice questions that were assessed in a Likert Scale, ranging from 1 (low) to 6 (high), and two open-ended questions. Through this questionnaire each version's strengths and weaknesses were found, and a comparison between SDV2 and SDv6 could be performed.

TABLE 1 - The questionnaire to evaluate satisfaction, motivation and collaboration.

\begin{tabular}{|c|c|}
\hline Group & Questions \\
\hline \multirow{5}{*}{ 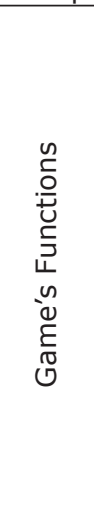 } & $\begin{array}{l}\text { Q1 - How was the quantity and clarity of } \\
\text { functionality information about the } \\
\text { game? }\end{array}$ \\
\hline & $\begin{array}{l}\text { Q2 - How easy was to understand the } \\
\text { functions of the game and to learn } \\
\text { how to play (interact with facts, re- } \\
\text { minders, curiosities and deposits)? }\end{array}$ \\
\hline & $\begin{array}{l}\text { Q3 - How was your motivation to move on } \\
\text { to the next levels of the game? }\end{array}$ \\
\hline & $\begin{array}{l}\text { Q4 - How would you grade the functions of } \\
\text { the game's interface? }\end{array}$ \\
\hline & $\begin{array}{l}\text { Q5 - How easy was to be oriented and to } \\
\text { navigate on the game? }\end{array}$ \\
\hline
\end{tabular}




\begin{tabular}{|c|c|}
\hline \multirow{4}{*}{ 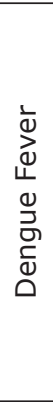 } & $\begin{array}{l}\text { Q6 - How was the clarity of the instructions } \\
\text { / information about dengue fever? }\end{array}$ \\
\hline & $\begin{array}{l}\text { Q7 - How much information have you lear- } \\
\text { ned about dengue fever? }\end{array}$ \\
\hline & $\begin{array}{l}\text { Q8 - How much do you intend to use this } \\
\text { game in the future to study dengue } \\
\text { fever? }\end{array}$ \\
\hline & $\begin{array}{l}\text { Q9 - How would you rate your level of con- } \\
\text { fidence to suggest this game to so- } \\
\text { meone else learn about dengue fever? }\end{array}$ \\
\hline \multirow{2}{*}{ 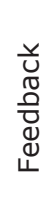 } & $\begin{array}{l}\text { Q10 - What are the most important streng- } \\
\text { ths of Sherlock Dengue } 6.0 ?\end{array}$ \\
\hline & $\begin{array}{l}\text { Q11 - What are the most important weak- } \\
\text { nesses of Sherlock Dengue } 6.0 \text { ? }\end{array}$ \\
\hline
\end{tabular}

SOURCE: Our authorship

To conduct the experiments, a testing protocol and an experiment description were designed. During the pre-test phase, participants were asked to use either the individual or the collaborative version of SD. Several pre-tests were performed with smalls groups ranging from 6 to 18 children, teenagers and youngsters, in sessions of $\mathbf{3 0}$ minutes long in average. All the attendees sign a written consent to participate in the experiments voluntarily.

\section{Results and Analysis}

Based on the participants' answers, a comparative analysis about satisfaction and motivation could be performed. As the target audiences for SD are children and teenagers aged between 8 to 15 years old, the data was analyzed in two steps: firstly considering just the answers from the target audience, and secondly considering all the answers - including the youngsters who also have participated.

\subsection{Target Audience Perception}

A total of 53 children and teenagers met the criteria as target audience. From this group, 35 used the individual version (SDv2) and 18 used the collaborative version (SDv6). SDv2 players, $51 \%$ male and $49 \%$ female, have 12.03 years of age on average $\left(\mu_{\text {age }}\right)$, with standard deviation $(\sigma) 2.61$, coefficient of variation $\left(c_{v}\right) 21.72 \%$, negative skew and platykurtic distribution, while SDv6 players, $83 \%$ male and $27 \%$ female, have $\mu_{\text {age }}=12.06$, with $\sigma=1.99, c_{v}=16.47 \%$, positive skew and platykurtic distribution.

The collected data as response to the objective questions (scale 0 to 6 ) of the questionnaire were grouped, analyzed and then compared. Figure 5 shows these data, presenting the average for each question (number inside the boxes) and their standard deviations (black vertical lines).

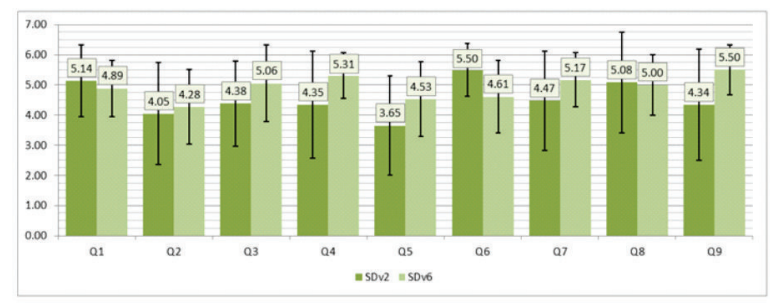

FIGURE 5 - Results obtained from the target audiences participants of the tests in response to the objective questions of the proposed questionnaire. SOURCE: Our authorship

The high rates for both SDv2 (at left) and SDv6 (at right) indicates good acceptance from the target audience, where the total average $\left(\mu_{\mathrm{T}}\right)$ of SDv6 was 4.93 and $\sigma=1.04$, and the total average $\left(\mu_{T}\right)$ of SDv2 was 4.55 and $\sigma$ $=1.53$. This result shows better acceptance of the collaborative version but statistically insignificant difference. 
Two aspects presented the biggest difference in $\mu$ : the clarity of instructions and information about dengue fever (Q6) was considered better for SDv2, while the confidence to show the game for someone else (Q9) was considered better for SDv6, both with $\mu=5.50$ and similar $\sigma=(0.87$ and 0.83$)$. The easiness of orientation and navigation (Q5) was the worst evaluated question in SDv2.

A linear correlation ( $r$ ) analysis between questions was also performed for each of the versions, but no strong correlation $(|r| \geq 0.7)$ has been found. Although, moderate correlations $(0.5 \leq|r|<0.7)$ has been found in SDv2, where $25.14 \%\left(r^{2}\right)$ of Q1 (quantity and clarity of functionality information) variance could be explained by Q4 (functions of the game interface) variance, $31.68 \%$ of Q4 variance were related to Q8 (intention to use the game for dengue fever studies) variance, and $31.75 \%$ of Q8 variance was also related to Q3 (motivation to continue playing). The relations between $\mathrm{Q} 8$ and Q4, and Q8 and Q3, indicates a possible tendency of future intention to use the game when the players fell satisfied with the functionalities of the game interface and when they are motivated to continue playing. No moderate correlation has been found in SDv6.

In order to compare the results of the individual and collaborative versions, the average differences were compared: SDV2 was better evaluated than SDv6 in Q6 (clarity of instructions and information about dengue fever) with $99.43 \%$ of confidence. This was a surprise since the content was exactly the same for both versions and the groups ages were almost the same. One possible explanation could be the difference in the background of the groups that could be confirmed in a more extensive demographic data collection. Or, the single-player version would allow better concentra- tion regarding the content. On the other hand, SDv6 outperformed SDV2 in five questions: Q3 (motivation to continue playing) with $92.19 \%$ of confidence, Q7 (information learned about dengue fever) with $95.27 \%$ of confidence, Q5 (easiness of orientation and navigation) with 96.99\% of confidence, Q4 (game's interface functionalities) with $99.40 \%$ of confidence, and Q9 (confidence to show the game to someone else) with $99.84 \%$ of confidence. Questions Q1, Q2 and Q8 had similar results in both game versions and their average difference could not be compared with high levels of confidence.

Considering this analysis, it is possible to conclude that, in general, the collaborative version was better evaluated than the individual version, with higher levels of confidence, by the target audience. The data suggest that, for the target audience, the collaborative version was more motivating and its players were more convinced to share it with friends.

\subsection{General Perception}

Considering all the participants of the tests target audience plus teenagers and youngsters that did not met the age criteria - the game was played by 113 people where 67 used the individual version and 48 used the collaborative version. In this analysis SDv2 players, $60 \%$ male and $40 \%$ female, had $\mu_{\text {age }}=15.30$, with $\sigma=4.25$, coefficient of variation $\left(c_{v}\right) 27.80 \%$, positive skew and platykurtic distribution, while SDv6 players, $74 \%$ male and $26 \%$ female, had $\mu_{\text {age }}=16.61$, with $\sigma=4.14, c_{v}=24.94 \%$, negative skew and platykurtic distribution.

All participants' answers to the objective questions of the questionnaire were again grouped, analyzed and then compared. Figure 6 shows the average for each question (num- 
ber inside the boxes) and their standard deviations (black vertical lines). Still, both versions were well assessed: $\mu_{\mathrm{T}}=4.61, \sigma=1.23$ in SDv6, and $\mu_{T}=4.48, \sigma=1.50$ in SDv2. This result indicates a good general acceptance, very similar to both individual and collaborative versions.

In this analysis, the higher and the lower rate was repeated in SDV2, where the clarity of instructions and information about dengue fever (Q6) obtained the best mean (5.40), and the easiness of orientation and navigation (Q5) obtained the worst mean (3.61). Considering all participants, SDv2 overall answers variance has decreased (0.03), whereas SDv6 overall answers variance has increased (0.19). Higher variances ( $\sigma$ bigger than 1.5 ) could be seen in Q4, Q5, Q8 and Q9 in SDv2, and in Q8 in SDv6.

A new linear correlation ( $r$ ) analysis between questions has been performed for each of the versions, but again no strong correlation $(|r|$ $\geq 0.7$ ) has been found. Although, moderate correlations $(0.5 \leq|r|<0.7)$ has been found, especially in SDv6: Q9 (confidence to show the game for someone else) was related to four other questions, where $32.36 \%$ of its variance could be explained by Q1 (quantity and clarity of functionality information) variance, 36.02\% by Q4 (game's interface functionality) variance, $36.27 \%$ by Q5 (easiness of orientation and navigation) variance, and $45.13 \%$ by Q8 (future intention to use the game) variance.

Moreover, $35.05 \%$ of Q8 variance was related to Q7 (information learned about dengue fever) variance and $29.12 \%$ of Q5 variance were related to Q4 variances.

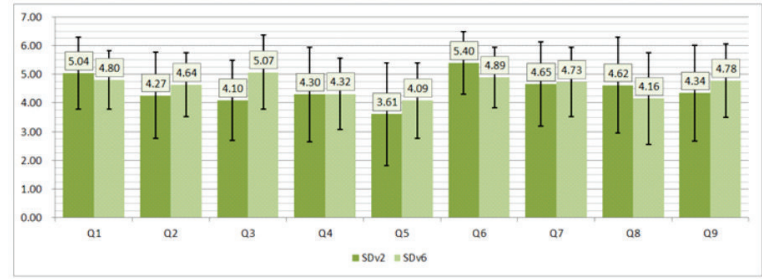

FIGURE 6 - Results obtained from all participants responses to the objective questions of the proposed questionnaire in the tests. SOURCE: Our authorship

In SDv2, Q8 variance were again related to Q3 (motivation to keep playing) (34.66\%) and Q4 (25.11\%) variances, and $26.99 \%$ of Q6 (clarity of instructions and information about dengue fever) variance was relate to Q1 variance.

The multiple relationship of Q9 must be highlighted: the players seem to care about the quantity and clarity of functionality information, the game interface, the easiness of orientation and navigation, and their intention to use the game again for study about dengue fever when indicating the SDv6 to someone else. These four aspects could be considered as motivators to share the game.

To perform a final comparison between the results of the individual and collaborative versions, the average differences were estimated again. SDv2 is still better evaluated than SDv6 in Q6 (confidence factor $c_{f}=98.70 \%$ ), and was also better evaluated in Q8 $\left(C_{f}=86.75 \%\right)$, and Q1 ( $\left.\mathrm{c}_{\mathrm{f}}=73.13 \%\right)$. However, SDv6 outperformed SDv2 in four other questions: Q2 $\left(c_{\mathrm{f}}=86.90 \%\right), \mathrm{Q9}\left(\mathrm{c}_{\mathrm{f}}=88.55 \%\right), \mathrm{Q} 5\left(\mathrm{c}_{\mathrm{f}}=\right.$ $89.87 \%)$, and Q3 ( $\left.C_{f}=99.99 \%\right)$. Questions Q4 and Q7 had similar results and its means difference could not be compared with high levels of confidence.

These results support the perception of the target audience, being plausible to conclude 
that, in general, both versions - individual and collaborative - were well accepted.

\subsection{Sherlock Dengue Strengths and Weaknesses}

Feedback was obtained from two open-ended questions whereby participants could inform their considerations about the strengths (Q10) and weaknesses (Q11) of SD. From question Q10, six SDv2 players and thirteen SDv6 players highlighted that the game is educational and helps in the learning process, one SDv2 player and five SDv6 players said the content theme - dengue fever - was interesting, one SDv2 player and three SDv6 players said the learning was fun, one SDV2 player said the game was easy to use, one SDv6 player said the graphics were pleasant and another SDv6 player said the game manipulation navigation and orientation - was good. From question Q11, seven SDv6 players complained about problems - malfunctions and crashes in the game, three SDv6 players disliked the graphics, two SDv6 players argued the game should have avatars for both genders, two SDv2 players complaint about the game's navigation, one SDv6 player said the movements were too slow, another dislike losing points when answering incorrectly, and another one complaint about the avatar.

It is important to emphasize that questions Q10 e Q11 were not answered by all the 113 players and included controversial point of views (e.g. some players liked the graphics and the manipulation but others did not). Regarding the game's problems complaints, some players have experienced some anomalies in the game; their session of use was interrupted and started again. This interruption could have influenced negatively the results.
In addition to the statistical analysis, at least two more positive aspects related to the collaborative play were noticed while monitoring the tests: some players had individualistic behaviors initially (same fact was observed in Hämäläine et al., 2006), but the gameplay have fostered collaboration and there was greater engagement of the participants using the chat to make plans and exchange information, which can be explained by social psychology, and; the players have achieved higher scores, being exposed to large amount of dengue fever information.

It should be noticed that the individual version is available through the internet (SHERLOCK..., 2013) and users can access it anytime without previous consent from a partner. This freedom and availability turns SDV2 as a reference tool for further consulting.

\section{Conclusion}

The fight against Dengue fever is a subject of considerable attention by public health agencies which seeks the disease prevention primarily through the educational process, teaching how to stop the mosquito proliferation. Thereby, an educational game could encourage people, especially children and teenagers, to know this problem and contribute to decreasing the mosquito deposit spots and therefore reducing the number of mosquito vectors and dengue infections. However, dengue fever prevention is not a one man problem. Therefore, neighbor's collaborative effort must be emphasized. A collaborative educational game can teach about dengue fever and increase the interaction between the game users. This collaborative version performs a fusion among teaching about dengue, social interactions, fun and entertainment. Two versions for a Serious 
Game to teach about Dengue fever, called Sherlock Dengue (SD), were built: one individual (SDv2) and other, collaborative (SDv6). Through a comparison between SDv2 and SDv6, it was found that both versions presented high acceptance by the target audience (and even by general youth public including children, teenagers and youngsters).

As a whole, it is plausible to say that the perceptions of a broader audience confirmed those of the target audience and suggests that both individual and collaborative versions performed well, but the collaborative one was slightly better on motivation and user's willingness to suggest the game to someone else.

The analysis took the users' perspective to satisfaction and motivation. Furthermore, the results show that players preferred collaborative interactions than playing individually. Thus, besides collaborative approaches have being considered better than individual ones from teacher's perspective (JOHNSON, R.T.; JOHNSON, D. 1988, ZEA et al. 2009, SUNG; HWANG, 2013), the players themselves did like collaboration more. These results stress the potentials of collaborative serious games.

This study compared individual and collaborative interactions, but there is the competition interaction among players which is another widely used form of interaction in games. Pareto et al. (2012) discussed the findings involving collaboration and competition altogether and some researches have shown good results through the use of these two interactions altogether. Thus, it raises the question: would a competitive-collaborative interaction (the mix of both interactions) be more effective than each alone? Further researches should tackle this question.

\section{Acknowledgements}

The authors would like to thank to PROMOP-UDESC for the scholarship grant, to professors Maurício Aronne Pillon and Carla Diacui Medeiros Berkenbrock, and also to Bárbara Nied, Emerson Brites de Maia e Gilberto Marques Junior from the City of Joinville Board of Health.

\section{References}

ALVAREZ, J.; DJAOUTI, D. An Introduction to Serious Game Definitions and Concepts. In: SERIOUS GAMES \& SIMULATION FOR RISKS MANAGEMENT WORKSHOP, 2011, Paris. Proceedings. Paris: Larsen Science, 2011. P. 11-15.

BILSEN, A.V.; BEKEBREDE, G.; MAYER, I. Understanding Complex Adaptive Systems by Playing Games. Informatics in Education, v. 19, n. 1, p. 1-18, 2010.

BOWMAN, R.F. A Pac-Man Theory of Motivation. Tactical Implications for Classroom Instruction. Educational Technology, v. 22, n. 9, p. 14-17, 1982. 
BOYLE, E.; CONNOLLY, T.M.; HAINEY, T. The Role of Psychology in Understanding the Impact of Computer Games. Entertainment Computing, v. 2, p. 69-74, 2011.

BRASIL. Ministério da Saúde. Portal da Saúde [site]. Brasília, 2013. Disponível em: <http://portal. saude.gov.br/portal/arquivos/pdf/dengue_classica_90_11_10_02_12.pdf> Acesso em: 27 mai. 2014.

BUCHINGER, D.; HOUNSELL, M.S. Sherlock Dengue 8: A Serious Game for Teaching about Dengue Fever Prevention with Collaboration and Competition. In: SIMPÓSIO BRASILEIRO DE JOGOS E ENTRETENIMENTO DIGITAL, 13., 2014, Porto Alegre, BR-RS. Proceedings. Porto Alegre: [s.n.], 2014. P. 400-409.

COLLAZOS, C.A. et al. Evaluating Collaborative Learning Process Using System-based Measurement. Educational Technology \& Society, v. 10, n. 3, p. 257-274, 2007.

CORTE, E. et al. Powerful Learning Environments: Unravelling Basic Components and Dimensions. Bingley: Emerald; Earli, 2003. (Advances in Learning and Instruction)

DIAS, C. et al. Design and Implementation of a 3D Collaborative Telerobotic Simulator. In: INTERNACIONAL CONFERENCE ON COLLABORATION AND TECHNOLOGY CRIWG'2011, 17., 2011, Parati, BR-RJ. Proceedings. Berlin: Springer, 2011. P. 207-214.

GUZMAN, A.; ISTÚRIZ, R.E. Update on the Global Spread of Dengue. International Journal of Antimicrobial Agents, v. 36, n. 1, S40-S42, 2010.

HÄMÄLÄINEN, R. et al. Learning to Collaborate: Designing Collaboration in a 3-D Game Environment. Internet and Higher Education, v. 9, p. 47-61, 2006.

HOUNSELL, M.S. et al. Ambiente Virtual 3D de Aprendizagem Sobre a Doença da Dengue. In: SIMPÓSIO BRASILEIRO DE INFORMÁTICA NA EDUCAÇÃO, 17., 2006, Brasília, BR-DF. [Anais]. Brasília: [s.n.], 2006a. V. 1, p. 477-486.

HOUNSELL, M.S. et al. Uma Plataforma de Teste Para o Projeto Auditivo de Ambientes Virtuais 3D com Propósitos Educacionais. In: SIMPÓSIO BRASILEIRO DE INFORMÁTICA NA EDUCAÇÃO, 17., 2006, Brasília, BR-DF. [Anais]. Brasília: [s.n.], 2006b. V. 1, p. 41-50.

HOUNSELL, M.S.; MIRANDA, J.J.; KEMCZINSKI, A. Estratégias de Avaliação da Aprendizagem em Ambientes Virtuais 3D e Jogos Sérios. In: INTERNATIONAL CONFERENCE ON ENGINEERING AND TECHNOLOGY EDUCATION, 11., 2010, Ilhéus, BR-BA. [Proceedings]. Ilhéus: CEPEDI, 2010. V. 1, p. 538-542. JOHNSON, R.T.; JOHNSON, D. Cooperative Learning: Two heads learn better than one. In Context: $A$ Quarterly of Humane Sustainable Culture, n. 18, p. 34, winter 1988. Tema do fascículo: Transforming 
Education: Awakening the full human potential... in everyone. Disponível em: <http://www.context. org/iclib/ic18/johnson/> Acesso em: 11 jun. 2014.

KEMCZINSKI, A.; MAREK, J.; HOUNSELL, M.S. Collaboration and Cooperation: Relevance, Competition or Complementarity. Revista Produção on-Line, v. 7, n. 3, p. 1-15, nov. 2007. Disponível em: < http:// www.researchgate.net/profile/Marcelo_Hounsell/publication/257984550_COLABORAO_E_COOPERAO_PERTINNCIA_CONCORRNCIA_OU_COMPLEMENTARIDADE/links/0c96053585616becec000000. pdf> Acesso em: 29 jun. 2014.

LENNON, J.L.; COOMBS, D.W. The Utility of a Board Game for Dengue Haemorrhagic Fever Health Education. Health Education, v. 107, n. 3, p. 290-306, 2006.

PADRÓS, A.; ROMERO, M.; USART, M. Measuring the Knowledge Convergence Process in the Collaborative game MetaVals. Procedia Computer Science, v. 15, p. 193-202, 2012.

PARASKEVA, F.; MYSIRLAKI, S.; PAPAGIANNI, A. Multiplayer online games as educational tools: Facing new challenges in learning. Computers \& Education, v. 54, p. 498-505, 2010.

PARETO, L. et al. A teachable-agent-based game affording collaboration and competition: evaluating math comprehension and motivation. Educational Technology Research and Development, v. 60, p. $723-751,2012$.

PEREIRA, P.F. et al. Considerações Para Jogos de Ação do Tipo Plataforma com Base nas Experiências do Desenvolvimento do Jogo Contra Dengue. In: BRAZILIAN SYMPOSIUM ON GAMES AND DIGITAL ENTERTAINMENT, 10., 2011, Salvador, BR-BA. Proceedings of SBGames 2011. Salvador: [s.n.], 2011 P. 1-4.

SCHMITZ, Q.T.; KEMCZINSKI, A.; HOUNSELL, M.S. Realidade Virtual no Treinamento da Inspeção de Focos de Dengue. In: WORKSHOP DE INFORMÁTICA APLICADA À SAÚDE, 4., 2004, Itajaí, BR-SC. Anais. [Joinville]: UDESC, 2004. V. 1, p. 541-546.

SHERLOCK Dengue [site]. Joinville: UDESC, 2013. Disponível em: <http://www2.joinville.udesc. br/ larva/dengue/>. Acesso em: 20 jul. 2014.

SILVA, V. et al. Exterminadores de Dengue: um jogo educativo dinâmico como ferramenta de educação contra a dengue. In: BRAZILIAN SYMPOSIUM ON GAMES AND DIGITAL ENTERTAINMENT, 10., 2011, Salvador, BR-BA. Proceedings of SBGames 2011. Salvador: [s.n.], 2011 P. 71-77.

STENROS, J.; PAAVILAINEN, J.; MÃYRÃ, F. The Many Faces of Sociability and Social Play in Games. In: INTERNATIONAL MINDTREK CONFERENCE: EVERYDAY LIFE IN THE UBIQUITOUS ERA, 13., 2009, Tam- 
pere, Finland. Proceedings. New York: ACM, 2009. P. 82-89.

SUNG, H.Y.; HWANG, G.J. A Collaborative Game-based Learning Approach to Improving Students' Learning Performance in Science Courses. Computers \& Education, v. 63, p. 43-51, apr. 2013.

TREVISAN, D.G. et al. Qual a Melhor Realidade Para Aprender Jogando: virtual ou aumentada? In: SIMPÓSIO BRASILEIRO DE JOGOS E ENTRETENIMENTO DIGITAL, 8., 2009, Rio de Janeiro, BR-RJ. Proceedings. Rio de Janeiro: [s.n.], 2009. P. 1-10.

VIVAS, E.; SEQUEDA, M.G. A game as an educational strategy for the control of Aedes aegypti in Venezuelan school children. Pan American Journal of Public Health, v. 14, n. 6, p. 394-401, 2003.

ZEA, N.P. et al. Design of Education Multiplayer Videogames: A Vision from Collaborative Learning. Advances in Engineering Software, v. 40, n. 12, p. 1251-1260, dec. 2009.

Submetido para avaliação em 24 de julho de 2014.

Aprovado para publicação em 18 de março de 2015.

Diego Buchinger - Universidade do Estado de Santa Catarina, Florianópolis, BR-SC.

E-mail: diego.buchinger@outlook.com

Marcelo da Silva Hounsell - Universidade do Estado de Santa, Florianópolis, BR-SC. E-mail: marcelo.hounsell@ udesc.br 